\title{
Customer! The Forgotten Stakeholder
}

\author{
Themistokles Lazarides, Stamatios Kontsas, Electra Pitoska \\ TEI of Western Macedonia, Grevena, Greece
}

\begin{abstract}
During last two decades a shift in marketing, corporate strategy, organizational, and market dynamics has been recorded. A series of corporate scandals like ENRON and others has shown that corporations have a significant impact on a number of stakeholders and particularly customers. The notion that the customers can shift from one product or service provider to the other may not be as valid as some theories suggest. The markets are not perfect mechanisms and customers are not rational decision makers. Although marketing has introduced the corporate culture- the customer-centric approach, the results are not as positive as they should be. The paper shows that marketing and corporate governance systems have many common elements and in fact they can be complementary in practice and theory. To establish the connection-correlation between them, the author is going to review the literature from both disciplines. As a next step, an analysis of impact of the customer as a party that has an interest in the firm is going to take place. Finally, two examples of this impact will depict the importance of a change in scope — goal, strategy, and practices used by both disciplines in achieving the firm's mission and goals. The author shows that both can be benefit from the integration of mechanisms, principles, and practices used by the marketing and corporate governance. The paper is the first step to create a theoretical convergence framework for these disciplines that seem completely separate. Marketing and corporate governance specialists and theorists may design a more comprehensive and holistic approach to customer that is more customer friendly, more long term and establishes a more successful and value creation (for both the customer and the corporation) relationship.
\end{abstract}

Keywords: corporate governance, marketing, customer

\section{Introduction}

Until now corporate governance and marketing were considered to be two different. Drucker's (2001) definition of marketing is:

Marketing and innovation are the two chief functions of business. You get paid for creating a customer, which is marketing. And you get paid for creating a new dimension of performance, which is innovation. Everything else is a cost center. (p. 31)

According to Drucker's definition, auditing, accounting, human resource management, etc. are secondary functions of the firm and the main focus should only be in marketing, research and development and production.

Themistokles Lazarides, Ph.D., Associate Professor, Applied Informatics in Administration and Economy, TEI of Western Macedonia.

Stamatios Kontsas, Ph.D., Adjunct Lecturer, Applied Informatics in Administration and Economy, TEI of Western Macedonia.

Electra Pitoska, Ph.D., Associate Professor, Financial Applications, TEI of Western Macedonia.

Correspondence concerning this article should be addressed to Themistokles Lazarides, Grevena, 51100, Greece. E-mail: themis@themis.gr. 
This approach of business has been dominant throughout the 1980s, 1990s, and the previous decade. What came as a surprise during the last 10 years was that customers found themselves in many cases to be without choices and loosing substantial assets, value or money by the lack of products and services.

The recent events, scandals, crises and the subsequent legal framework and business' redesign of their functions and priorities show a shift in the business approach towards the market, the customer, the stakeholder and especially their role in the economy. A new consciousness is formulating. They corporations seem to understand or they beginning to understand that the customer-centric approach is to narrow to achieve their goals and mission. The main cause of the shift is the change in corporate mission and goals in the new approach of the economy and market.

This does not mean that the customer-centric approach has no merit any more. It is a fact that the customer-centric approach was short-term and narrow in scope. In the era of accelerated decline of the product life cycle, product complexity, huge capital invested, and enormous sizes of corporations' innovation per se cannot create the foundations for sustainable corporate growth (i.e., the "war" between Apple and Samsung for the table computer). Notions like stability, respect, accountability, ethos, corporate fame, and trust have become important to the customer. Hence, corporations have begun to realize that success cannot be achieved by looking outward (marketing), but inward as well (corporate governance).

\section{Corporate Governance Approaches}

There are many theories-approaches for corporate governance but only one is incorporating the customer as an interesting party in the corporate agenda. The main theories that do not incorporate the customer are: (1) Managerial hegemony theory (Mace, 1971; Vance, 1983; Lorsch \& MacIver, 1989) which mainly focuses on the dominant position of managers at the top administrative and monitoring corporate bodies; (2) Resource dependence theory. According to this theory, boards of directors can be the facilitators of obtain resources form the corporate environment and adapting to this environment (Pfeffer, 1972, 1973; Pfeffer \& Salancik, 1978; Pearce \& Zahra, 1991; Goodstein, Gautam, \& Boeker, 1994); (3) Agency theory (Barney \& Hesterly, 1996; Eisenhardt, 1988, 1989; Davis, 1991; Fama \& Jensen, 1983; Jensen \& Fama, 1983; Fama, 1980; Jensen \& Meckling, 1976, 1994). The agency theory argues that there are principals (owners, shareholders) and agents (managers). Both parties are rationally committed, opportunistic, risk averse and selfish. The main problem that the theory recognizes is the alignment of interests between principals and agents.

The only theory of corporate governance that explicitly or implicitly incorporates the customer is the stakeholders theory. According to the stakeholder approach (Freeman, 1984; Donaldson \& Preston, 1995; Vinten, 2000, 2001) all parties that have potentially an interest or risk in the firms' function can or must be involved in its governing process. In the economic literature, many of the parties have been analyzed to define the influence and their impact on the firm's performance or on the governing process.

Despite the obvious interaction that exists between a firm and not directly engaged parts in the decision making process and the governance of the firm, the stakeholder approach has received a lot of criticism by both practitioners and academics. It was only until recently when the growing concern of society for matters as environmental protection, corporate responsibility, and the rising power of consumers' protection associations, that triggered a fruitful discussion on the role of customers as a stakeholder in a firm. 
Sternberg (1997), an opponent of the stakeholder theory has expressed some arguments that according to her invalidate the stakeholder theory. The arguments can be categorized into four groups:

(1) Stakeholder theory is incompatible with business.

Stakeholder theory argues that none of the interesting parties should be favored when choosing corporate goals. The diffusion of focus, or focus on cross many goals—stakeholders lead to reduced effectiveness.

The holistic definition of stakeholders creates a potentially very large set of stakeholders and a correspondingly large set of interests. This number is not manageable. This led some to try to limit the number of interested parties on three, four, or more groups. One of the problems of selecting and grouping specific number of stakeholders is the fact that a person may be a member of more than one group (e.g., the executive manager can be a shareholder; the shareholder may be a creditor, etc.).

From the above it appears that the stakeholder theory describes a large number of parties, large sets of interests, and high degrees of significance interest. How the company's management will achieve in designing a methodology for achieving equilibrium between these many combinations? The goal appears unattainable and therefore the theory, according to Sternberg, is incompatible with entrepreneurship per se. Faced with this dilemma, the leadership of the administration is more likely to choose the most commonly accepted company goal or mission and exclude groups and parties that they seem that they have no bargaining power or influence in the company's management.

(2) Stakeholder theory is incompatible with corporate governance.

One of the most important principles of corporate governance is accountability (the others are responsibility, fairness, and transparency (OECD, 2004; Fremond \& Capaul, 2002)). The stakeholder theory argues that the management should be accountable to all stakeholders. Accountability diffusion reduces its efficiency, respectively, because accountability has a specific aim: to explain the mechanism—process of fulfilling the objectives and results of operations have been performed. The large number of targets because of the large number of stakeholders makes accountability chaotic and therefore ineffective.

The lack of weights and measures, by which to make comparisons is another disadvantage. The lack of comparative analysis of the accountability process reduces the efficiency and pertinence. So the dominant parties are not accountable to anyone.

The most extreme view of Sternberg (1997) is that by reporting and balancing the executives or the company's management with all stakeholders violates an important corporate governance mechanism, the confidence with which they invested shareholders when managers hired.

(3) Stakeholder theory of accountability is unjustified.

The logic of the theory is that the company's success will come from the creation of long-term mutually beneficial relationships with all stakeholders. These relationships are critical success factor of the strategic objectives of the company and may directly contribute even to maximize financial performance. Sternberg and other liberal theorists argue that this argument should not serve as a pretext for the extension of accountability to all stakeholders.

The second question is purely moral. The stakeholder theory argues that relations with all parties should be based mainly on strong and lasting relationships interdependent stakeholders, both at home and abroad of the company environment. According to this theory, the only targets that should the company make are those 
that achieve a balance between all and can be considered common. The question of Sternberg is: Why exclude the objectives of individual parties that are not common and because the company is not accountable for them?

A third argument is a parallel with the government. Interested parties are "citizens" of a peculiar state and have corresponding rights and especially the right of accountability. Sternberg (1997, p. 6) argues that the parallelism does not apply because the governments have a monopoly of power and the right to use force, which does not apply to corporations. The company is based on voluntary organizations and not pushing or forcing anyone to do anything. There is always the option of leaving companies and no one can argue the same for a country's citizens.

A final argument for accountability is that companies use resources of society to achieve their goals and therefore the company should be accountable to society for the use of these resources. This creates a "contract" between the company and society. The "contract" is an informal non-explicit regarding the fallout of the rights and obligations of both parties and does not include additional methods of enforcing terms.

(4) Stakeholder theory undermines ownership, representation, and wealth.

The diffusion of monitoring and supervision to all stakeholders is equivalent to the loss of ownership. The owner—shareholder may designate the use of his property or to exercise control over the use of his property.

... the fact that property rights may be weakly enforced provides no justification for violating them. An overworked or lazy police force may make theft easier to accomplish; it does not give robbers the right to one's goods. Despite what stakeholder theorists suggest, the fact that shareholders are sometimes unwilling or unable actively to protect their interests does not entitle other stakeholders to commandeer corporate property. (Sternberg, 1997, p. 8)

The diffusion of responsibility that agents have to everyone, rather than just to shareholders, is undermining the relationship between agents and shareholders. The undermining of the critical partnerships can have devastating effects on the functional and organizational balance.

The stakeholder theory has its roots in the continental-German and Japanese model of corporate governance, where the influence of stakeholders is taken under greater consideration when designing strategies and selecting objectives for the company. In these models the concept of business is institutional and investment time horizon is long. These differences create an identification of capital owner with the company, and thus, the capitalist will place greater emphasis on relations with the environment inside the company because he realizes that over time these relationships are those that create stability within the business and growth prospects.

\section{Marketing}

Marketing during the last four decades has made a significant impact on the business environment and changed dramatically the way corporations are creating—selecting strategies, developing product and services, organizing their structures and departments and mostly allocating their resources. The importance of marketing is shown by the statement of Drucker (discussed in the Introduction section of the paper) and its inclusion to every curriculum of business schools around the world. Although marketing is so important or because of it scholars and practitioners do not agree on one single definition. The better definitions are focused upon customer orientation and satisfaction of customer needs. As shown by the definitions below, marketing is evolving and adapting to the new business environment and especially to the expectations of the customer for 
the corporation.

"Marketing is the social process by which individuals and groups obtain what they need and want through creating and exchanging products and value with others” (Kotler, 1994).

"Marketing is the management process that identifies, anticipates, and satisfies customer requirements profitably" (The Chartered Institute of Marketing (CIM)).

The CIM definition (in common with Barwell's definition of the marketing concept) looks not only at identifying customer needs, but also satisfying them (short-term) and anticipating them in the future (long-term retention).

"The right product, in the right place, at the right time, at the right price" (Adcock). This is a snappy and realistic definition that uses McCarthy's 4Ps.

"Marketing is essentially about marshalling the resources of an organization so that they meet the changing needs of the customer on whom the organization depends” (Palmer). This is a more recent and very realistic definition that looks at matching capabilities with needs.

During the last two decades a change in defining marketing has taken place. In 1994, a definition of societal marketing (applicable to not-for-profit organizations such as charities or schools) appeared:

Marketing is the process whereby society, to supply its consumption needs, evolves distributive systems composed of participants, who, interacting under constraints—-technical (economic) and ethical (social)—create the transactions or flows which resolve market separations and result in exchange and consumption. (Bartles, 1968, p. 32)

The societal marketing concept holds that the organization's task is to determine the needs, wants, and interests of target markets and to deliver the desired satisfactions more effectively and efficiently than competitors, in a way that preserves or enhances the consumer and the society's well-being.

Marketing scholars and practitioners now are promoting the idea that marketing is all about creating long term successful relations with customers. Marketing is shifting its time horizon from short to long term and from 4Ps to relationship building.

\section{Marketing and Corporate Governance in the Post Scandals Era}

For many years the basic framework for firms was that marketing can offer the customer-centric approach as a tool to achieve the satisfaction of their customers. Firms use the marketing process or function to promote their products and services, in order to maximize the firm's performance and customer satisfaction. Therefore marketing processes and strategies can and must be held accountable for the relationship among a firm and her customers.

Market inflexibilities, imperfections or inefficiencies can lock customer to his/hers selection. Hence customers have an interest in firm's operation, since product discontinue, or failure to uphold its promise to deliver the product at the appropriate and agreed time, place and condition can have an enormous effect on the customers performance, well being, and satisfaction. Customer is the base on which the firm functions and operates. Effective markets have a significant impact on the governing and marketing process. The pseudo customer-centric approach used by many firms that expropriate customers can lead to low quality management, business ethics, and corporate governance.

The basic framework of the paper is that marketing can offer the customer-centric approach as a tool to 
achieve the stakeholder approach. Firms are using marketing process or function to promote their products and to maximize the firm's performance and customer satisfaction. Marketing can and must be accountable for the relationship among the firm and the customer. As marketing is taking up a considerable amount of both assets and financial resources (almost 25 percent of expenditures is directly attributed to marketing), is also responsible, in part, for the financial results (sales, profits, and cash flows). Marketing expenditures have the goal to retain and expand the customer base. An expanding, financially successful, firm must change organizationally to address the new issues raised by the challenges of the sales size and growth rate. Managers may overinvest in marketing strategies, or in the creation of new products (R\&D), in the hope of increasing market share, through sales, with beneficiary effects on their salary (bonus), and their reputation in the managerial labor market. However that behavior can be damaging for the interests of shareholders as it can lead to overinvestment and reduced profits for the firm in the short run. An expanding, financially successful, firm must change organizationally to address the new issues raised by the challenges of the sales size and growth rate, not only for her existing and new customers but also for the shareholders as well.

The direct connection between the financial results and marketing has lead to an organizational and cultural change that for some firms is implicit and for some other explicit. The driving factor of marketing to organizational change is the need to focus on customer needs. The paradox is that even though marketing has been the driving force behind the firms' performance and change, organizational economics has shown very little value to the customer as a stakeholder.

A firm can, using the marketing process-practices or techniques, to attract customers. Market inflexibilities, imperfections or inefficiencies can lock customer to his/hers selection. Hence, customers have an interest in firm's operation, since product discontinue, or failure to uphold its promise to deliver the product at the appropriate and agreed time, place and condition can have an enormous effect on the customers performance, well being, and satisfaction. Customer is the base on which the firm functions and operates. Effective markets have a significant impact on the governing and marketing process. The pseudo customer-centric approach used by many firms that expropriate customers can lead to low quality management, business ethics, and corporate governance.

Marketing and corporate governance are interconnected. They have some commonalities and some differences. The commonalities are:

(1) Mechanisms. Both corporate governance and marketing use the same fundamental mechanisms: Trust, reputation, implicit, and explicit contracts.

(2) They are process oriented.

(3) They are interest-performance or value focused.

(4) They both have a need for an internal control mechanisms and audit protocols.

(5) Information plays a crucial role in determining the effectiveness, the policies, principles, practices, and the structures used.

(6) There are the same options: loyalty, voice, and exit.

(7) The integration of marketing and corporate governance is driven by corporate culture.

(8) Activism (stakeholder-shareholder and customer) can play a significant role in achieving excellence and stability. 
The differences are:

(1) Marketing is outbound and corporate governance is mainly an inbound process.

(2) Marketing focuses on customer alone, whereas corporate governance focus is broader in scope.

\section{Examples}

The cases used in this paper have some common characteristics. The first one is that both firms were located in USA and they both are in sectors that customers-people find that consumption is inflexible (energy and communications). The second one is that both use long term contracts with their customers.

\section{Enron}

"Enron Corp." manipulated the energy market practically every day during the 2000-2001 power crunch and gouged Western customers for at least $\$ 1.1$ billion, according to audiotapes and documents released yesterday.

The records were uncovered by the same utility that last month released details of profanity-laced conversations in which Enron traders gleefully gloat about ripping off "those poor grandmothers" in California during the power crisis.

The latest release by the Snohomish Public Utility District provides another glimpse into how Enron allegedly rigged the market at the same time millions of Californians were suffering blackouts and paying sky-high electricity bills.

Snohomish wants an administrative law judge to order Enron to surrender up to \$2 billion in ill-gotten gains. California politicians want Enron to reimburse customers there at least $\$ 8.9$ billion.

The latest documents show that Enron manipulated the market on 473 of 537 days from January 2000 to June 2001, the utility said “...Enron filed for bankruptcy in 2001” (Retrieved from http://www.baltimoresun.com/business/bal-bz.enron15jun15,0,6782458.story).

The example of Enron shows that the firm failed to incorporate in its culture the customer-centric approach and mostly failed to create long term relationships with its customers

\section{WorldCom (Feder, 2002)}

In the case of WordCom, customers were concerned about the availability of service:

“The vast majority of WorldCom's customers are residential users of standard long-distance and local phone service. But the ones that hold the key to its future are large telecommunications, government, and business customers. WorldCom is the world's largest carrier of Internet traffic, and many of these customers buy Internet capacity from the company's UUNet subsidiary or obtain private data networks or other highly profitable services from other WorldCom units.

Many large customers are likely to stick with WorldCom as long as the company maintains service levels, if only because shopping elsewhere might force them to buy from several vendors what they receive in one deal from WorldCom. Only AT\&T can match WorldCom’s scope.

In addition, some major customers are bound by contracts running as long as three years that they cannot easily escape".

Customers as shown in these two examples are stakeholders that have significant interest in the normal 
operation, function, and viability of the corporation. Corporations that failed to realize the notion of stakeholder and the customer-centric approach didn't succeed. Furthermore, they have created a climate of distrust and market anxiety to customers and other market participants.

\section{Conclusions}

The paper has shown that the two disciplines-sciences have much in common and they can work complimentarily in order to create a new approach-framework for the understanding of the corporate environment. Both of them are considered cornerstones of business successes and their shortcoming or failure cornerstones of business failures. The degree of importance for the two disciplines is different and varies from sector to sector and from country to country. Nevertheless corporations that ignore them is almost certain that will fail in the modern corporate environment.

Empirical research is needed in order to validate the theory that these two disciplines can converge and find common ground. If the empirical research validates the connection then there is a strong connection between organizational economics, financial analysis and marketing and the new marketing's definition can have more emphasis on the stakeholder approach than the previous one.

\section{References}

Barney, J. B., \& Hesterly, W. S. (1996). Organizational economics: Understanding the relationship between organizations and economic analysis. In S. R. Clegg, C. Hardy, \& W. R. Nord (Eds.), Handbook of organization studies. Thousand Oaks, C.A.: Sage Publications Ltd..

Bartles, R. (1968). The general theory of marketing. Journal of Marketing, 32, 29-33.

Davis, G. F. (1991). Agents without principles? The spread of the poison pill through the intercorporate network. Administrative Science Quarterly, 36(4), 583-613.

Donaldson, T., \& Preston, L. (1995). The stakeholder theory of the modern corporation: Concepts, evidence and implications. Academy of Management Review, 20, 65-91.

Drucker, P. (2001). The essential Drucker. N.Y.: HarperCollins Publisher.

Eisenhardt, K. M. (1988). Agency-and institutional-theory explanations: The case of retail sales compensation. Academy of Management Journal, 31(3), 488-511.

Eisenhardt, K. M. (1989). Agency theory: An assessment and review. Academy of Management Review, 14(1), 57-74.

Fama, E. F. (1980). Agency problems and the theory of the firm. Journal of Political Economy, 88(2), 288-307.

Fama, E., \& Jensen, M. (1983). Separation of ownership and control. Journal of Law and Economics, 26, 301-325.

Feder, B. (2002). Worldcom's collapse: The customers; Many think service won't decline further. Retrieved from http://www.nytimes.com/2002/07/22/us/worldcom-s-collapse-the-customers-many-think-service-won-t-decline-further.html? pagewanted $=$ all\&src $=$ pm

Freeman, R. E. (1984). Strategic planning: A stakeholder approach. Marshfield, M.A.: Pitman Publishing.

Fremond, O., \& Capaul, M. (2002). The state of corporate governance: Experience from country assessments. World Bank Policy Research Working Paper 2858.

Goodstein, J., Gautam, K., \& Boeker, W. (1994). The effects of board size and diversity on strategic change. Strategic Management Journal, 15, 241-250.

Jensen, M. C., \& Fama, E. F. (1983). Agency problems and residual claims. Journal of Law and Economics, 26, 327-349.

Jensen, M. C., \& Meckling, W. H. (1994). The nature of man. Journal of Applied Corporate Finance, 7(2), 4-19.

Jensen, M., \& Meckling, W. (1976). The theory of the firm: Managerial behavior, agency costs, and ownership structure. Journal of Financial Economics, 3, 305-360.

Kotler, P. (1994). Marketing management: Analysis, planning, implementation and control (8th ed.). Englewood Cliffs, New Jersey: Prentice Hall. 
Lorsch, J. W., \& MacIver, E. (1989). Pawns or potentates: The reality of America's corporate boards. Boston: Harvard Business School Press.

Mace, M. L. G. (1971). Directors: Myth and reality. Boston: Division of Research Graduate School of Business Administration Harvard University.

OECD. (2004). OECD principles of corporate governance. Paris: OECD.

Pearce, J. A. II., \& Zahra, S. A. (1991). The relative power of CEOs and boards of directors: Associations with corporate performance. Strategic Management Journal, 12, 135-153.

Pfeffer, J. (1972). Size and composition of corporate boards of directors: The organization and its environment. Administrative Science Quarterly, 17, 218-228.

Pfeffer, J. (1973). Size, composition, and function of hospital boards of directors: A study of organization—Environment linkage. Administrative Science Quarterly, 18, 349-364.

Pfeffer, J., \& Salancik, G. R. (1978). The external control of organizations: A resource dependence perspective. New York: Harper \& Row.

Sternberg, E. (1997). The defects of stakeholder theory. Corporate Governance: An International Review, 5(1), 3-10.

Vance, S. C. (1983). Corporate leadership: Boards, directors, and strategy. New York: McGraw-Hill.

Vinten, G. (2000). The stakeholder manager. Manager Decision, 38(6), 377-383.

Vinten, G. (2001). Shareholder versus Stakeholder-Is there a governance dilemma? Corporate Governance: An International Review, 9(1), 36-47.

Zahra, S. A., \& Pearce, J. A. II. (1989). Boards of directors and corporate financial performa: A review and integrative model. Journal of Management, 15, 291-334. 